\title{
EFICÁCIA DOTESTE DE ACIDEZ GRAXA NA AVALIAÇÃO DA QUALIDADE DO CAFÉ ARÁBICA (Coffea arabica L.) SUBMETIDO A DIFERENTE PERÍODOS E TEMPERATURAS DE SECAGEM
}

\author{
Efficiency of fatty acidity test on the evaluation of the quality of \\ arabic coffee (C.A) submitted to different dry periods and temperatures \\ Elizabeth Rosemeire Marques ${ }^{1}$, Flávio Meira Borém², \\ Rosemary Gualberto Fonseca Alvarenga Pereira ${ }^{3}$, Marco Antônio Martin Biaggioni ${ }^{4}$
}

\begin{abstract}
RESUMO
Conduziu-se este trabalho, com o objetivo de avaliar o efeito de diferentes temperaturas e períodos de pré-secagem em terreiro na composição química e qualidade da bebida do café $1 / 2$ cereja descascada $1 / 2$. Foram usadas temperaturas na massa de $40^{\circ} \mathrm{C}, 50^{\circ} \mathrm{C}$ e $60^{\circ} \mathrm{C}$ com fluxo de ar de $20 \mathrm{~m}^{3} \mathrm{~m}^{-1} \mathrm{~m}^{2}$. Após a secagem, foram retirados os defeitos visíveis das amostras de café. Para avaliação da qualidade, foram realizadas as seguintes análises: análise sensorial, açúcares totais, açúcares redutores e não redutores, condutividade elétrica, lixiviação de potássio e acidez graxa. Verificou-se que menores temperaturas de secagem e um maior período de pré-secagem contribuíram para obtenção de uma bebida de melhor qualidade. Os açúcares não redutores diminuíram com o aumento da temperatura e com o aumento da pré-secagem, enquanto que elevaram-se os valores de açúcares redutores. A condutividade elétrica, lixiviação de potássio e acidez graxa aumentaram significativamente com a elevação da temperatura e a lixiviação de potássio reduziu com o aumento do período de pré-secagem. O teste de acidez graxa mostrou-se sensível a temperatura de secagem.
\end{abstract}

Termos para indexação: Secagem, composição química, bebida, Coffea arabica L.

\section{ABSTRACT}

This work had the aim of evaluating the effect of different temperatures and pre-drying periods on yard on the chemical composition and quality of the beverage of peeled cherry coffee. Temperatures of $40^{\circ} \mathrm{C}, 50^{\circ} \mathrm{C}$ and $60^{\circ} \mathrm{C}$ were used in the mass with air flow of $20 \mathrm{~m}^{3} \mathrm{~m}^{-1} \mathrm{~m}^{2}$. After drying, the visible defects of the coffee samples were removed. For evaluation of quality, the following analyses were performed: sensorial analyses, total sugars, reducing sugars and non- reducing sugars, electrical conductivity, potassium leaching and fatty acidity. One verified that lower drying temperature and greater pre-drying period had contributed for the attainment of a better quality drink. The increase of temperature and pre-drying periods decreased the non-reducing sugars content while the values of reducing sugars increased. The electrical conductivity, potassium leaching and fatty acidity increased significantly with the rise of temperature and potassium leaching reduced with increasing of the pre-drying period. The fatty acidity test showed to be sensible to the drying temperature.

Index terms: Drying, parchment coffee, drink, Coffea arabica L.

(Recebido em 28 de abril de 2006 e aprovado em 16 de julho de 2007)

\section{INTRODUÇÃO}

Para que o café seja considerado de qualidade, as propriedades químicas, físicas e sensoriais devem estar de acordo com os padrões estabelecidos. A qualidade do café como bebida é determinada pelo sabor e aroma, que estão associados às substâncias químicas existentes no grão e que são influenciados pela temperatura e taxa de secagem. Os estudos desenvolvidos nesse sentido abrangem componentes como açúcares, proteínas, compostos fenólicos, enzimas, lipídeos, bem como umidade, condutividade elétrica dos grãos e lixiviação de potássio, entre outros (BÁRTHOLO et al., 1989; PEREIRA, 1997).

$\mathrm{Na}$ literatura, existem relatos sobre os danos causados pela secagem em grãos de café, os quais comprometem a obtenção de uma bebida de boa qualidade. Acredita-se que isso seja devido à desorganização e à desestruturação das membranas celulares, permitindo que os componentes químicos, antes compartimentalizados, entrem em contato com enzimas hidrolíticas e oxidativas, afetando as características de cor, sabor e aroma da bebida. Conhecer estas alterações provocadas pela secagem torna-

${ }^{1}$ Agrônoma, Doutoranda - Departamento de Fitotecnia - Universidade Federal de Viçosa/UFV - 36570-000 - Viçosa, MG - Bolsista CAPES bethagro@yahoo.com.br

${ }^{2}$ Agrônomo, PhD. - Departamento de Engenharia/DEG - Universidade Federal de Lavras/UFLA - Cx. P. 3037 - $37200-000$ - Lavras, MG flavioborem@ufla.br

${ }^{3}$ Farmacêutica, Doutora - Departamento de Ciência dos Alimentos/DCA - Universidade Federal de Lavras/UFLA - Cx. P. 3037 - $37200-000$ - Lavras, MGrosegfap@ufla.br

${ }^{4}$ Agrônomo, Doutor, Professor Assistente - Departamento de Engenharia Rural - Faculdade de Ciências Agronômicas/FCA - Universidade Estadual Paulista/UNESP - Fazenda Experimental Lageado - Rua José Barbosa de Barros, 1780 - Cx. P. 237 - 18603-970 - Botucatu, SP-biaggioni@fca.unesp.br 
se importante na tentativa de minimizar os seus efeitos (PRETE, 1992; RIBEIRO, 2003).

Vários trabalhos evidenciaram a existência da relação entre a desorganização das membranas celulares e a perda de constituintes dos grãos, com o aumento da quantidade de exsudados determinados na água de embebição (MARCOS FILHO et al., 1990; PRETE, 1992).

Prete (1992) verificou uma relação inversa entre a qualidade da bebida e a condutividade elétrica e a lixiviação de potássio, determinados no exsudato de grãos crus.

Sob condições adversas de manejo pós-colheita, uma das primeiras reações que ocorrem é a formação de ácidos graxos livres. Durante o armazenamento, a hidrólise do material graxo inicia-se antes da hidrólise de carboidratos ou proteínas (BIAGGIONI \& FERREIRA, 1998). Barros (2004) observou uma tendência dos teores de ácidos graxos livres acompanhar a classificação comercial do arroz por tipos. Assim, quanto pior o tipo comercial de grãos de arroz, maiores os teores de ácidos graxos livres.

Pesquisas utilizando o teste de acidez graxa em grãos de café ainda não foram realizadas. Dessa forma, neste trabalho, objetivou-se caracterizar química e sensorialmente o café submetido a diferentes temperaturas e períodos de pré-secagem e detectar o potencial do teste de acidez graxa em determinar alterações na qualidade do café (Coffea arabica L.).

\section{MATERIAL E MÉTODOS}

Este trabalho foi desenvolvido no Setor de Sementes do Departamento de Agricultura, no Laboratório de Qualidade do Café Dr. Alcides Carvalho da EPAMIG em Lavras MG e no Pólo de Tecnologia em Qualidade do Café da Universidade Federal de Lavras.

O produto utilizado foi o café Arábica (Coffea arabica $L$.), plantado em altitude de $918,841 \mathrm{~m}$, latitude de $21^{\circ} 14^{\prime} \mathrm{S}$ e longitude de $45^{\circ} 00 \mathrm{~W}$, sendo preparado na forma de $1 / 2$ cereja descascado $1 / 2$. Na tentativa de diminuir a interferência de diferentes matérias-prima nos resultados, utilizou-se em todo o experimento apenas a cultivar Catucaí. A colheita foi realizada manualmente, pelo sistema de derriça no pano; em seguida, procedeu-se a separação hidráulica de todo o café em função da densidade dos frutos. Da porção formada pelo café verde mais o $1 / 2$ cereja $1 \frac{1}{2}$ foi descascado e, posteriormente, submetido à pré-secagem em terreiro. Para realizar a pré-secagem, o café foi esparramado em terreiro de concreto no início da noite do mesmo dia em que foi colhido, em camadas de aproximadamente $1 \mathrm{~cm}$ e revolvido durante o dia a cada 30 minutos.
O café foi submetido a dois períodos de présecagem, 1 e 3 dias de terreiro. Para cada colheita, foram colhidos cerca de $0,9 \mathrm{~m}^{3}$ de café; foram realizadas duas colheitas para cada repetição. Em seguida, o café foi dividido em doze parcelas iguais, permanecendo aleatoriamente no terreiro, seis dessas parcelas por apenas um dia e as demais por três dias, para redução do teor de água. Os valores médios da temperatura e da umidade relativa do ar foram de $15,7^{\circ} \mathrm{C}$ e $74 \%$ respectivamente. Após a pré-secagem, amostras foram retiradas para se determinar o teor de água no início da secagem nos secadores. A determinação do teor de água foi realizada pelo método padrão de estufa $105 \pm 3^{\circ} \mathrm{C}$ por 24 horas (BRASIL, 1992). Após a pré-secagem no terreiro, o café foi submetido à secagem em três secadores de camada fixa, a uma espessura de $0,13 \mathrm{~m}$, utilizando-se fluxo de ar de $20 \mathrm{~m}^{3} \mathrm{~min}^{-1} \mathrm{~m}^{-2} \mathrm{e}$ três temperaturas médias na massa de café $\left(40,50\right.$ e $\left.60^{\circ} \mathrm{C}\right)$ em quatro repetições no tempo.

Os secadores experimentais de camada fixa utilizados possuíam uma câmara de 0,61 x 0,61 x 0,61m, um elemento de expansão e um ventilador centrífugo acionado por um motor de $0,5 \mathrm{cv}$. A câmara Plenum continha um conjunto de resistências elétricas de $3.400 \mathrm{kw}$ para aquecimento do ar de secagem e a câmara de secagem era composta por quatro divisões removíveis que receberam quatro das doze amostras pré-secadas no terreiro. Cada divisão recebeu, em média, $0,01 \mathrm{~m}^{3}$ de café.

Após cada secagem e resfriamento, amostras foram retiradas para determinação do teor de água final do café pelo método padrão de estufa a $105 \pm 3{ }^{\circ} \mathrm{C}$ durante 24 horas. Em seguida, as amostras foram acondicionadas em embalagens de polietileno até o momento do beneficiamento para a realização das análises sensoriais e químicas.

Os defeitos visíveis das amostras de café como: verde, ardido, preto, brocado, chocho, mal granado e quebrado foram retirados antes da realização das análises, a fim de evitar que os grãos defeituosos interferissem nos resultados.

A qualidade da bebida foi avaliada pela $1 / 2$ prova de xícara $1 \frac{1}{2}$ realizada no Pólo de Tecnologia em Qualidade do Café da Universidade Federal de Lavras, por um provador credenciado, funcionário do Ministério da Agricultura. Foram provadas três amostras de cada tratamento em cada repetição, totalizando 144 amostras (3 amostras x 12 tratamentos x 4 repetições no tempo), de acordo com a Instrução Normativa $n^{\circ} 08$, de julho de 2003 (BRASIL, 2003).

Para a determinação da condutividade elétrica dos grãos crus adaptou-se a metodologia desenvolvida por 
Krzyanowski et al. (1991), citado por Vieira (1994). Foram utilizadas duas repetições de 50 grãos sem defeitos visíveis de cada amostra, os quais foram pesados em balança com precisão de $0,001 \mathrm{~g}$ e imersos em $75 \mathrm{~mL}$ de água deionizada no interior de copos plásticos de $180 \mathrm{~mL}$ de capacidade. A seguir, estes recipientes foram colocados em estufa ventilada regulada para $25^{\circ} \mathrm{C}$ por 5 horas, procedendo-se à leitura da condutividade elétrica da solução em aparelho DIGIMED CD-20 a cada intervalo de 30 minutos. Com os dados obtidos foi calculada a condutividade elétrica, expressando-se o resultado em $\mathrm{mScm}^{-1} \mathrm{~g}^{-1}$ de amostra.

Após a leitura da condutividade elétrica, realizouse a determinação da lixiviação dos íons de potássio das soluções segundo metodologia proposta por Prete (1992). A leitura foi realizada em fotômetro de chama DIGIMED NK-2002. Com os dados obtidos foi calculado o potássio lixiviado, expressando-se os resultados em ppm.

A acidez graxa foi determinada por titulação, de acordo com o método 02-02A (método rápido de acidez graxa para grãos), modificado como descrito na AACC (1995). A moagem das amostras foi realizada em moinho refrigerado e na extração utilizou-se um agitador que serviu como um misturador (tolueno + café moído) durante 90 minutos. Para expressar o resultado em $\mathrm{mL}$ de $\mathrm{KOH} / 100 \mathrm{~g}$ de matéria seca, foram realizadas as correções de acordo com o teor de água e a massa da amostra moída. Para calcular os teores de ácidos graxos livres, utilizou-se a seguinte equação:

$$
\begin{aligned}
& \mathrm{PS}=(1-\mathrm{Ubu}) \times 40 \mathrm{~g} \\
& \text { Teor de } \mathrm{AG}=\frac{\mathrm{V} \times 100}{\mathrm{MS}}
\end{aligned}
$$

Em que:

MS = massa da amostra seca $(\mathrm{g})$

Ubu = umidade base úmida (\%)

$40 \mathrm{~g}$ de grão moído

$\mathrm{V}=$ volume gasto de $\mathrm{KOH}$ na titulação da mistura (extrato + indicador) $\mathrm{em} \mathrm{mL}$

$\mathrm{AG}=$ acidez graxa $(\mathrm{mL}$ de $\mathrm{KOH} / 100 \mathrm{~g}$ de matéria seca).

Os açúcares totais e redutores foram extraídos pelo método de Lane-Enyon, citado por AOAC (1990) e determinados pela técnica de Somogy, adaptada por Nelson (1944). Os açúcares não-redutores foram determinados pela diferença entre os açúcares totais e os redutores. Foi utilizada uma análise de covariância em que adotou-se o modelo fatorial (2x3). A covariável utilizada foi a umidade final. Convém salientar que, preliminarmente à realização dessa análise, foi verificado se a umidade final poderia interferir nos tratamentos representados pela combinação das temperaturas $(40,50$ e $60^{\circ} \mathrm{C}$ ) e períodos de secagem ( 1 e 3 dias). Considerou-se ser adequado o uso desta covariável caso a mesma não interferisse no efeito dos tratamentos avaliados pela significância do teste $\mathrm{F}$.

A análise de variância realizada para a variável açúcar redutor foi feita considerando a transformação $\sqrt{\mathrm{x}+5}$. A apresentação das médias foi feita na escala original dos dados. No entanto, a realização do teste de Tukey considerou o quadrado médio residual, dado pela análise de variância dos dados transformados. O software utilizado para a realização das análises foi o SAS versão 8e. As médias foram submetidas ao teste de Tukey, a 5\% probabilidade.

\section{RESULTADOS E DISCUSSÃO}

\section{Açúcares totais}

Para os açúcares totais, não houve diferenças significativas $(\mathrm{P}<0.05)$ entre os tratamentos estudados, entretanto Ribeiro (2003) ao avaliar a qualidade do café preparado na forma de $1 / 2$ cereja descascado $1 / 2$ submetido a três temperaturas de secagem 40,45 e $50^{\circ} \mathrm{C}$, verificou uma redução dos teores de açúcares totais, de $9,02 \%$ para $8,71 \%$ com o aumento da temperatura de 40 para $50^{\circ} \mathrm{C}$.

\section{Açúcares redutores}

Na Tabela 1 estão apresentados os teores de açúcares redutores obtidos sob efeito de dois períodos de pré-secagem (PS).

Tabela 1 -Teores médios de açúcares redutores sob efeito de dois períodos de pré-secagem a que foram submetidas e preparadas na forma de "cereja descascada".

\begin{tabular}{cc}
\hline Pré-secagem (dias) & Açúcares redutores (\%) \\
\hline 1 & $0,38 \mathrm{~b}$ \\
3 & $0,48 \mathrm{a}$ \\
\hline
\end{tabular}

Médias seguidas pela mesma letra não diferem entre si,a 5\% de probabilidade, pelo teste de Tukey.

Verificaram-se diferenças significativas $(\mathrm{P}<0,01)$ entre os teores de açúcares redutores sob os períodos de pré-secagem a que foram submetidas as amostras de café. Observou-se que houve uma elevação nos teores de açúcares redutores com o aumento do período de présecagem.

\section{Açúcares não-redutores}

Os teores de açúcares não redutores sob efeito da temperatura é apresentado na Tabela 2. 
Tabela 2 - Teores médios para açúcares não redutores em amostras de café preparadas na forma de "cereja descascada" submetidas a três temperaturas de secagem.

\begin{tabular}{cc}
\hline Temperatura $\left({ }^{\circ} \mathrm{C}\right)$ & Açúcares não redutores $(\%)$ \\
\hline 40 & $10,41 \mathrm{a}$ \\
50 & $10,11 \mathrm{ab}$ \\
60 & $9,64 \mathrm{~b}$ \\
\hline
\end{tabular}

Médias seguidas pela mesma letra não diferem entre si, a 5\% de probabilidade, pelo teste de Tukey.

Verificaram-se diferenças significativas $(\mathrm{P}<0,05)$ entre as diferentes temperaturas de secagem que foram submetidas às amostras de café, observando-se uma redução nos teores de açúcares não redutores, com o aumento da temperatura de 40 para $60^{\circ} \mathrm{C}$. Estes resultados assemelham-se aos encontrados por Ribeiro (2003) que, estudando três temperaturas de secagem 40,45 e $50^{\circ} \mathrm{C}$, verificou uma redução dos teores de açúcares não redutores, de $8,72 \%$ para $8,40 \%$ com o aumento da temperatura de 40 para $50^{\circ} \mathrm{C}$.

\section{Condutividade elétrica e lixiviação de potássio}

Após a análise de variância dos valores de condutividade elétrica e de lixiviação de potássio em função da temperatura (T) aplicada ao café, em dois períodos de pré-secagem (PS), observou-se que os efeitos de (T) e de (PS) foram significativos a 5\% de probabilidade.

Os resultados obtidos de condutividade elétrica e de lixiviação de potássio de grãos de café preparados na forma de "cereja descascada", submetidos à diferentes temperaturas de secagem, encontram-se na Tabela 3.

Tabela 3-Valores médios de condutividade elétrica e lixiviação de potássio em grãos de café submetido na forma de "cereja descascada", submetidos a três temperaturas de secagem.

\begin{tabular}{ccc}
\hline $\begin{array}{c}\text { Temperatura } \\
\text { de secagem } \\
\left({ }^{\circ} \mathrm{C}\right)\end{array}$ & $\begin{array}{c}\text { Condutividade } \\
\text { elétrica } \\
\left(\mu \mathrm{Scm}^{-1} \mathrm{~g}^{-\mathbf{1}}\right)\end{array}$ & $\begin{array}{c}\text { Lixiviação } \\
\text { de Potássio } \\
(\mathrm{ppm})\end{array}$ \\
\hline 40 & $174,444 \mathrm{c}$ & $50,729 \mathrm{c}$ \\
50 & $195,334 \mathrm{~b}$ & $67,429 \mathrm{~b}$ \\
60 & $231,657 \mathrm{a}$ & $85,239 \mathrm{a}$ \\
\hline
\end{tabular}

Médias seguidas pela mesma letra não diferem entre si a $5 \%$ de probabilidade, pelo teste de Tukey.

Observou-se uma relação positiva ou crescente entre as duas variáveis, encontrando-se, na temperatura de $60^{\circ} \mathrm{C}$, maiores valores de condutividade elétrica e lixiviação de potássio, mostrando o efeito da temperatura de secagem na degradação de membranas.

Ribeiro (2003), estudando a condutividade elétrica e a lixiviação de potássio em grãos de café preparados na forma de "cereja descascada" submetidos a três temperaturas de secagem $\left(40,45\right.$ e $\left.50^{\circ} \mathrm{C}\right)$, nos fluxos de ar e em dois períodos de pré-secagem, observou maiores valores de condutividade elétrica e de lixiviação de potássio para grãos secados à temperatura de $50^{\circ} \mathrm{C}$

Na tabela 4, é apresentado o efeito do período de pré-secagem na lixiviação de potássio do café preparado na forma de $1 / 2$ cereja descascado $1 / 2$.

Tabela 4 - Teores médios de potássio lixiviado, obtidos em amostras de café preparados na forma de" cereja descascado", submetidos a dois períodos de pré-secagem no terreiro.

\begin{tabular}{cc}
\hline Pré- Secagem (dias) & Potássio lixiviado (ppm) \\
\hline 1 & $71,093 \mathrm{a}$ \\
3 & $64,505 \mathrm{~b}$ \\
\hline
\end{tabular}

Médias seguidas de mesma letra não diferem entre si pelo teste de Tukey, ao nível de 5\% de probabilidade.

Observou-se que ocorreu uma redução significativa $(\mathrm{P}<0,05)$ nos teores de potássio lixiviado em café submetido a dois períodos de pré-secagem, menor quando se aumentou o período, correspondendo aos maiores teores de açúcares redutores.

Os testes de lixiviação de potássio e a condutividade elétrica são indicadores da integridade das membranas celulares. Portanto, maiores valores de condutividade elétrica e lixiviação de potássio correspondem a maiores danos nestas membranas.

\section{Acidez graxa}

A análise de variância dos valores de acidez graxa em função da temperatura de secagem (T) e do período de pré-secagem (PS) indicou haver diferença significativa, a $5 \%$ de probabilidade $(\mathrm{P}<0,05)$, para a interação $\mathrm{T} * \mathrm{PS}$.

$\mathrm{O}$ efeito da temperatura em amostras de café submetidas a dois períodos de pré-secagem encontra-se na Tabela 5 .

Tabela 5 -Teores médios de acidez graxa ( $\mathrm{ml}$ de $\mathrm{KOH} / 100 \mathrm{~g}$ MS) em grãos de café preparados na forma de "cereja descascada", submetidos a diferentes períodos de présecagem e a três temperaturas de secagem.

\begin{tabular}{ccc}
\hline Temperatura $\left({ }^{\circ} \mathrm{C}\right)$ & \multicolumn{2}{c}{ Período de pré-secagem (dias) } \\
\hline & 1 & 3 \\
40 & $2,42 \mathrm{cA}$ & $2,30 \mathrm{cA}$ \\
50 & $2,68 \mathrm{bA}$ & $2,73 \mathrm{bA}$ \\
60 & $2,98 \mathrm{aA}$ & $3,04 \mathrm{aA}$ \\
\hline
\end{tabular}

Médias seguidas de mesma letra minúscula nas colunas e maiúscula nas linhas não diferem entre si, pelo teste de Tukey, a $5 \%$ de probabilidade. 
Observa-se que houve um maior acréscimo do teor de acidez graxa com o aumento da temperatura, entretanto, não houve diferenças significativas em relação aos dois períodos de pré-secagem. Soares (2003), estudando a acidez graxa em sementes de soja submetidas a altas temperaturas de secagem, verificou maiores deteriorações em consequiência da ocorrência de maiores teores de acidez graxa, em sementes submetidas à secagem drástica.

Esses resultados estão relacionados à estabilização das membranas e à integridade das paredes celulares, indicando que uma maior degradação das membranas celulares dará origem à maior quantidade de ácidos graxos livres (SALAZAR et al., 1994). Esses resultados indicam o potencial para a utilização do teste de acidez graxa em trabalhos de avaliação da qualidade do café.

\section{Qualidade da bebida}

Os resultados da "prova de xícara" das três amostras por repetição, em função da temperatura e período de pré-secagem, encontram-se na Tabela 6.

Tabela 6 - Classificação, utilizando-se a "prova de xícara", do café preparado na forma de "cereja descascada", quando submetido a três temperaturas e dois períodos de pré-secagem.

\begin{tabular}{|c|c|c|c|}
\hline \multirow[t]{2}{*}{ Bloco } & \multirow{2}{*}{$\begin{array}{c}\text { Temperatura } \\
\left({ }^{\circ} \mathrm{C}\right)\end{array}$} & \multicolumn{2}{|c|}{ Período de Pré-secagem (dias) } \\
\hline & & 1 & 3 \\
\hline \multirow{5}{*}{ I } & 40 & Mole & $\begin{array}{l}\text { Estritamente } \\
\text { mole }\end{array}$ \\
\hline & 40 & Mole & $\begin{array}{l}\text { Estritamente } \\
\text { mole }\end{array}$ \\
\hline & 50 & $\begin{array}{l}\text { Apenas } \\
\text { mole }\end{array}$ & $\begin{array}{l}\text { Estritamente } \\
\text { mole }\end{array}$ \\
\hline & 50 & Dura & $\begin{array}{l}\text { Estritamente } \\
\text { mole }\end{array}$ \\
\hline & 60 & Dura & $\begin{array}{l}\text { Estritamente } \\
\text { mole }\end{array}$ \\
\hline \multirow{7}{*}{ II } & 60 & Dura & $\begin{array}{l}\text { Apenas } \\
\text { mole }\end{array}$ \\
\hline & 40 & Mole & $\begin{array}{l}\text { Estritamente } \\
\text { mole }\end{array}$ \\
\hline & 40 & $\begin{array}{c}\text { Estritamente } \\
\text { mole }\end{array}$ & $\begin{array}{l}\text { Estritamente } \\
\text { mole }\end{array}$ \\
\hline & 50 & Dura & Mole \\
\hline & 50 & Dura & Mole \\
\hline & 60 & $\begin{array}{l}\text { Apenas } \\
\text { mole }\end{array}$ & Mole \\
\hline & 60 & $\begin{array}{l}\text { Apenas } \\
\text { mole }\end{array}$ & Dura \\
\hline
\end{tabular}

Tabela 6 - Continuação...

\begin{tabular}{|c|c|c|c|}
\hline \multirow{5}{*}{ III } & 40 & $\begin{array}{l}\text { Apenas } \\
\text { mole }\end{array}$ & Mole \\
\hline & 40 & $\begin{array}{l}\text { Apenas } \\
\text { mole }\end{array}$ & $\begin{array}{l}\text { Estritamente } \\
\text { mole }\end{array}$ \\
\hline & 50 & Dura & $\begin{array}{l}\text { Apenas } \\
\text { mole }\end{array}$ \\
\hline & 50 & $\begin{array}{l}\text { Apenas } \\
\text { mole }\end{array}$ & Mole \\
\hline & 60 & $\begin{array}{l}\text { Apenas } \\
\text { mole }\end{array}$ & $\begin{array}{l}\text { Apenas } \\
\text { mole }\end{array}$ \\
\hline \multirow{7}{*}{ IV } & 60 & $\begin{array}{l}\text { Apenas } \\
\text { mole }\end{array}$ & $\begin{array}{l}\text { Apenas } \\
\text { mole }\end{array}$ \\
\hline & 40 & $\begin{array}{l}\text { Apenas } \\
\text { mole }\end{array}$ & $\begin{array}{c}\text { Estritamente } \\
\text { mole }\end{array}$ \\
\hline & 40 & Dura & $\begin{array}{l}\text { Estritamente } \\
\text { mole }\end{array}$ \\
\hline & 50 & $\begin{array}{c}\text { Estritamente } \\
\text { mole }\end{array}$ & Dura \\
\hline & 50 & $\begin{array}{l}\text { Apenas } \\
\text { mole }\end{array}$ & Mole \\
\hline & 60 & $\begin{array}{l}\text { Apenas } \\
\text { mole }\end{array}$ & $\begin{array}{c}\text { Apenas } \\
\text { mole }\end{array}$ \\
\hline & 60 & $\begin{array}{c}\text { Apenas } \\
\text { mole }\end{array}$ & $\begin{array}{l}\text { Estritamente } \\
\text { mole }\end{array}$ \\
\hline
\end{tabular}

\section{CONCLUSÕES}

A partir dos resultados obtidos conclui-se que: o teor de acidez graxa aumenta significativamente com a elevação da temperatura de secagem;

menor temperatura de secagem e maior período de pré-secagem contribuíram para a obtenção de uma bebida de melhor qualidade;

a temperatura de $40{ }^{\circ} \mathrm{C}$ favorece a obtenção de cafés de melhor qualidade.

\section{AGRADECIMENTOS}

Os autores agradecem à FAPEMIG e ao CNPq pelo apoio financeiro dado a esse trabalho.

\section{REFERÊNCIAS BIBLIOGRÁFICAS}

AMERICAN ASSOCIATION OF CEREAL CHEMISTS.

Methods 02-02A: fat acidity: rapid method, for grain. Saint Paul, 1995. v. 1.

ASSOCIATION OF OFFICIAL ANALYTICAL CHEMISTS. Official methods of analysis of the Association of Official Analytical Chemists. 15. ed. Washington, DC, 1990.

BARROS, R. E. Teste de acidez graxa na avaliação da qualidade de arroz. 2004. 65 p. Dissertação (Mestrado em Agronomia) - Universidade Estadual Paulista, Botucatu, 2004. 
BÁRTHOLO, F. G.; MAGALHÃES FILHO, A. A. R. de; GUIMARÃES, P. T. G.; CHALFOUN, S. M. Cuidados na colheita, no preparo e no armazenamento do café. Informe Agropecuário, Belo Horizonte, v. 14, n. 162, p. 33-44, jul 1989.

BIAGGIONI, M. A. M.; FERREIRA, W. A. Variação na germinação e nível de ácidos graxos livres durante o armazenamento de milho colhido mecanicamente. In: CONGRESSO BRASILEIRO DE ENGENHARIA AGRÍCOLA, 27., 1988, Poços de Caldas. Anais... Lavras: UFLA/SBEA, 1998.

BRASIL. Ministério da Agricultura, Pecuária e Abastecimento. Instrução normativa n. 8, de 11 de junho de 2003. 2003.

BRASIL. Ministério da Agricultura e Reforma Agrária. Regras para análise de sementes. Brasília, DF, 1992. 365 p.

MARCOS FILHO, J.; SILVA, W. R. D. A.; NOVEMBRE, A D. C.; CHAMMA, H. M. C. P. Estudo comparativo de métodos para a avaliação da qualidade fisiológica de sementes de soja, com ênfase ao teste de condutividade elétrica. Pesquisa Agropecuária Brasileira, Brasília, v. 25, n. 12 , p. $1805-1815$, dez. 1990

NELSON, N. A photometric adaptation of the Somogyi method for the determination of glucose. Journal of Biological Chemists, Baltmore, v. 153, n. 1, p. 375384, 1944
PEREIRA, R. G. F. A. Efeito da inclusão de grãos defeituosos na composição química e qualidade do café (Coffea arabica $L$.) "estritamente mole". 1997. 96 f. Tese (Doutorado em Ciência dos Alimentos) - Universidade Federal de Lavras, Lavras, 1997.

PRETE, C. E. C. Condutividade elétrica do exsudato de grãos de café (Coffea arabica $L$.) e sua relação com a qualidade da bebida. 1992. 125 f. Dissertação (Mestrado em Agronomia) - Escola Superior de Agricultura Luiz de Queiroz, Piracicaba, 1992.

RIBEIRO, D. M. Qualidade do café cereja descascado submetido a diferentes temperaturas, fluxos de ar e períodos de pré-secagem. 2003. 86 p. Dissertação (Mestrado em Ciência dos Alimentos) - Universidade Federal de Lavras, Lavras, 2003.

SALAZAR, G. M. R.; RIANO, H. N. M.; ARCILA, P. J.; PONCED, C. A. Studio morfológico, anatômico y ultraestrutural del fruto de café Coffea arábica L. Cenicafé, Caldas, v. 45, n. 3, p. 93-105, 1994.

SOARES, T. A. Análise da acidez graxa como índice de qualidade em grãos de soja. 2003. 74 f. Dissertação (Mestrado em Agronomia) - Universidade Estadual Paulista, Botucatu, 2003.

VIEIRA, G. Secagem intermitente de café em secadores de fluxo cruzado e secador experimental de camada fixa. 1994. 91 f. Dissertação (Mestrado em Ciência dos alimentos) Universidade Federal de Lavras, Lavras, 1994. 